\title{
475694 - A DOUBLE-BLIND PLACEBO-CONTROLLED COMPARISON OF 4 FIXED DOSE PHENYLEPHRINE INFUSION REGIMENS FOR PROPHYLAXIS OF SPINAL-INDUCED HYPOTENSION DURING CESAREAN DELIVERY
}

\author{
Ronald George, MD FRCPC ${ }^{1}$, Terrence Allen, MBBS FRCA ${ }^{2}$, Holly Muir, MD \\ FRCPC $^{2}$, William White, MPH ${ }^{2}$, Ashraf Habib, MB ChB MSc FRCA ${ }^{2}$ \\ 1. Department of Women's \& Obstetric Anesthesia, IWK Health Centre, Halifax, \\ NS, Canada \\ 2. Division of Women's Anesthesia and Critical Care, Duke University Medical \\ Center, Durham, NC, USA
}

Introduction: The most commonly investigated regimen of phenylephrine (PE) infusion, starting at a dose of $100 \mathrm{mcg} / \mathrm{min}$, has been associated with reactive hypertension suggesting that lower doses may be more appropriate (1). This study investigates the dose of $\mathrm{PE}$ associated with the least number of physician interventions needed to maintain systolic blood pressure (SBP) within $20 \%$ of baseline.

Methods: With IRB approval 109 ASA 1-2 parturients undergoing CD with spinal anesthesia were enrolled. Parturients were allocated to four treatment groups [PE 25mcg/min (PE25), 50mcg/min (PE50), 75mcg/min (PE75), 100mcg/min (PE100)] or placebo (PE0). After three baseline SBP measurements patients received a standard spinal (12mg bupivacaine, $15 \mathrm{mcg}$ fentanyl, and 150mcg morphine). Immediately after the spinal, the blinded infusion was started along with a $20 \mathrm{ml} / \mathrm{kg}$ crystalloid coload. Hemodynamic data was collected every minute for the first 10 minutes and then every 2.5 minutes until 10 minutes after delivery when the infusion was stopped. A decrease in SBP $>20 \%$ of baseline or a SBP $<90 \mathrm{mmHg}$ was treated with $100 \mathrm{mcg}$ boluses of PE. An increase in SBP $>20 \%$ of baseline stopped the infusion. The infusion was restarted if the SBP returned within $20 \%$ of baseline.Glycopyrrolate was used to treat bradycardia ( $<50 \mathrm{bpm}$ ). The number of interventions needed to maintain SBP within $20 \%$ of baseline including the administration of PE boluses, stopping or restarting the infusion, and administration of glycopyrrolate were recorded. The number of hypotensive (SBP $<20 \%$ of baseline) and hypertensive (SBP $>20 \%$ of baseline) episodes were also recorded for each group. Statistical analysis was done for all pair wise comparisons using the Fisher and Kruskal Wallis test with adjustments made for multiple comparisons using stepdown permutations.

Results: Eight subjects did not complete the study. Demographics, duration of surgery, volume of fluid infused, estimated blood loss, incidence of nausea and vomiting, and the need for rescue antiemetics were similar among the groups. The results are shown in the table. Phenylephrine $50 \mathrm{mcg} / \mathrm{min}$ and $25 \mathrm{mcg} / \mathrm{min}$ were associated with significantly fewer interventions to maintain SBP within $20 \%$ of baseline when compared with $100 \mathrm{mcg} / \mathrm{min}$. A dose of $50 \mathrm{mcg} / \mathrm{min}$ reduced the incidence of hypotension and the number of hypotensive episodes when compared with placebo. A dose of $100 \mathrm{mcg} / \mathrm{min}$ was associated with more hypertension while significantly reducing the incidence of nausea. Discussion: All infusion regimes significantly reduced the incidence of hypotension when compared with placebo. $\mathrm{PE}$ at $50 \mathrm{mcg} / \mathrm{min}$ or less significantly reduced the number 
of physician interventions needed to maintain maternal SBP within $20 \%$ of baseline. References: 1.Anesthesiology 2005;103:744-50.

\begin{tabular}{|c|c|c|c|c|c|}
\hline & $\begin{array}{c}\text { PE0 } \\
(\mathbf{n = 2 0})\end{array}$ & $\begin{array}{c}\text { PE25 } \\
(\mathbf{n = 2 0})\end{array}$ & $\begin{array}{c}\text { PE50 } \\
(\mathbf{n = 2 0 )}\end{array}$ & $\begin{array}{c}\text { PE75 } \\
(\mathbf{n = 1 9 )}\end{array}$ & $\begin{array}{c}\text { PE100 } \\
(\mathbf{n = 2 2})\end{array}$ \\
\hline No. of interventions & $2(1-3.5)$ & $0.5(0-4.5)$ & $1.5(0-3.5)$ & $4(1-6)$ & $5(4-6)^{*}$ \\
\hline Pre-delivery hypotension & $16(80 \%) * *$ & $6(30 \%)$ & $3(15 \%)$ & $2(11 \%)$ & $0(0 \%)$ \\
\hline $\begin{array}{c}\text { Pre-delivery } \\
\text { hypertension }\end{array}$ & $2(10 \%) \dagger$ & $5(25 \%)$ & $8(40 \%)$ & $14(74 \%)$ & $18(82 \%) \dagger$ \\
\hline No. of hypotensive episodes & $2.65 \pm 2.45 \div$ & $0.9 \pm 1.37$ & $0.2 \pm 0.52$ & $0.47 \pm 1.17$ & $0.09 \pm 0.29$ \\
\hline No. of hypertensive episodes & $0.35 \pm 1.35 \%+$ & $1.2 \pm 2.33$ & $1.15 \pm 1.57$ & $2.79 \pm 2.46$ & $4.5 \pm 3.85$ \\
\hline Hypotension induced nausea & $7(35 \%)$ & $4(20 \%)$ & $1(5 \%)$ & $2(11 \%)$ & $0(0 \%) \S$ \\
\hline
\end{tabular}

Data are median (IQR), number (\%), or mean \pm sd ${ }^{*} \mathrm{p}=0.004$ vs PE50, $\mathrm{p}=0.02$ vs PE25

$* * \mathrm{p}=0.001$ vs $\mathrm{PE} 50, \mathrm{P}=0.0001$ vs $\mathrm{PE75}, \mathrm{p}<0.0001$ vs $\mathrm{PE} 100$

$\dagger \mathrm{p}=0.0006$ vs $\mathrm{PE75}, \mathrm{p}<0.0001$ vs $\mathrm{PE} 100$

$\dagger \dagger \mathrm{p}=0.008$ vs PE25

$\ddagger \mathrm{p}=0.002$ vs PE25, $\mathrm{p}<0.0001$ vs PE50, PE75, \& PE100

$¥+\mathrm{p}<0.0001$ vs PE100

$\S \mathrm{p}=0.04$ vs PE0 